\title{
STUDIESOF THE OTTOMANDOMAIN
}

Cilt:1 Sayı:1 Ağustos 2011

Issn: $2147-5210$

www.thestudiesofottomandomain.com

\section{Sözlü Tarihin Vesikalardaki Yansımaları: Velioğlu Ahmed Efendi Cinayeti}

\author{
Prof. Dr. Yasemin Demircan ${ }^{1}$
}

\begin{abstract}
Özet
Velioğlu Ahmed Efendi, XIX. yüzyılın ortalarında Sinop'ta görevli bir idareciydi. Faaliyetleri, yöredeki varlıklı bazı kişilerin husumetini celp etmesine yol açmıștı. Nihayet Ahmed Efendi, 7 Haziran 1854 günü öldürüldü. Ailesinin başlattığı hukuk mücadelesiyle, önce katil ile ona yardım ve yataklık eden kişi, ardından cinayetin azmettiricileri yakalanarak cezalandırıldı. Bu korkunç hatıra, günümüzde mesleki gailelerle Türkiye'nin çeşitli yerlerinde yaşayan ancak bir kuşak öncesine kadar Sinop İli'nin Ayancık İlçesi'ne bağlı Zaviye Köyü'nde ikamet etmiş olan Ayancıklı Velioğullarının hafızasında yer etmiş, nesilden nesle aktarılmıştır. Bir aile mirası olarak sözlü biçimde varlığını koruyan bu anıdan hareketle, olayın arşiv vesikalarına yansımaları tespit edilerek, ailesinin geçmişine merak duyan amatör yahut profesyonel araştırmacılara örnek bir çalışma ortaya çıkarmaya gayret edilmiştir.
\end{abstract}

Anahtar Kelimeler: Sinop Ayancık, Velioğulları, Sözlü Tarih, Yerel Tarih

\section{Summary}

Ahmed Efendi, was an administrator in Sinop towards the middle of the XIXth century. His activities led to antagonistic attitudes among some wealthy people in the region. Finally, Ahmed Efendi, was killed on June 7,1854 . According to the legal struggle launched by his family, the person, aiding and abetting the murderer, the murderer and at last the instigators of the murder had been captured and punished.However, this horrible event was engraved in the memories of the members of the Velioğulları family and passed over from generation to generation, who used to live at the Zaviye village in Ayanc1k, province of Sinop, but now living at various parts of Turkey because of professional achievements and conditions. Starting from this family heritage, which preserved its presence as an oral transmission, it is aimed to present a sample case study for amateur or professional researchers who are interested in the history of their ancestors by investigating the event according to the reflections in the archive documents.

Key Words: Sinop Ayancik, Velioghlu, Narrative history, domestic history.

\footnotetext{
${ }^{1}$ Gazi Üniversitesi, Eğitim Fakültesi, Tarih Eğitimi Anabilim Dalı, Ankara/Türkiye
} 
Tarihin, mesleki ve akademik bir araştırma sahası olmasının dışında amatör ilgiye ne denli mazhar olduğu hususu izahtan varestedir. Tarihe dönük bu ilgi pek çok insan için özellikle aile geçmişine dönük meraktan beslenmektedir. Bu merak ise “aile” özelinde ortak bir belleğin oluşmasına yol açtığı gibi geçmişe dair hatıraların sürekli canlı tutulmasını da sağlamıştır. XIX. yüzyılın ortalarında Sinop'ta görevli bir idareci olan Velioğlu Ahmed Efendi'nin cinayete kurban gitmesi de acı bir hatıra olarak, Ayancıklı Velioğullarının belleklerindeki yerini neredeyse iki yüzyıl korumuştur. Velioğulları günümüzde başta Karadeniz coğrafyası olmak üzere geniş bir sahada yaşamaktadır. Ailenin bir kolunun da XIX. yüzyılın ortalarında Sinop'a gelerek yerleştiği anlaşılmaktadır. Bu çalışmada farklı türde belgeler kullanılmıştır. Dolayısıyla köklü bir ailede kuşaklar boyu sözlü olarak aktarılan herhangi bir olayın tespiti, çoğu zaman tesadüflere dayanan güç bir araştırma sürecine dayanmaktadır. Bu keyfiyet Velioğlu Ahmed Efendi'nin öldürülmesini tarihte benzerine sıkça rastlanabilecek sıradan bir cinayet olmanın ötesine taşımakta, benzeri çalışmalara katkı sağlayabilecek bir örnek haline getirmektedir.

Ayancıklı Velioğulları, bir kuşak öncesine kadar Ayancık'a bağlı Zaviye Köyü'nde ikamet etmekteydiler. XIX. yüzyıla ait nüfus kayıtları içinde 1845 tarihli defterde Zaviye ile ilgili bilgilere rastlanmaktadır. ${ }^{2}$ Söz konusu defterden hareketle Zaviye'nin idarî pozisyonuna dair tespitlerde bulunmak mümkündür. Öncelikle Zaviye'nin, yöredeki birkaç köyü içine alan ve “divan” adı verilen ufak bir idarî birim olduğu anlaşılmaktadır. Defterdeki ifadelerden Zaviye'nin, Kastamonu Livası'na tâbi olup geçmişi M.Ö. XIV. yüzyıla kadar inen ve bir Bizans devri kalesine ev sahipliği yapan Kinoli (Ginoli) ${ }^{3}$ Kazası'nın idarî sınırları

\footnotetext{
${ }^{2}$ Başbakanlık Osmanlı Arşivi (BOA), Nüfus Defterleri (NFS), nr. 824, s. 50-57.

$3 \mathrm{Bu}$ yer çağlar boyunca farklı isimlerle anılmıştır. Örneğin antik devir kaynaklarından Plinius buray1 "Cimolis" şeklinde anar. Bkz. The Natural History of Pliny, (haz. John Bostock, H.
} 
dâhilinde olduğu belirlenebilmektedir. ${ }^{4}$ Aynı döneme ait arazî kayıtları ise Zaviye Divanı'nın daha sonra Bolu Eyaleti'ne tâbi bir kaza olan İstefan'a ${ }^{5}$ bağlandığını göstermektedir. ${ }^{6}$ İstefan Kazası esasen yöredeki Hristiyan ahali ile meskûn yerlerden biriydi. ${ }^{7}$ Ancak 1889 tarihli bir belgede kazanın zamanla bu özelliğini yitirdiği açık bir şekilde ifade edilmektedir. Söz konusu belgeye göre ahali burayı "Ayancık" adıyla anmaktaydı ve bu adın "İstefan"1n yerine geçmesini talep etmişlerdi. Nitekim devlet merkezinde de bu isteğe kayıtsız kalınmamış, İstefan'ın resmen "Ayancık" namıyla anılması yolunda adımlar atılmıştır.

Ailenin varlığına işaret eden belgelere bakıldığında 1855 tarihinde İstefan Kazası'nın müdürü olarak tanıtılan Mehmed Emin oğlu Ahmed Efendi ile karşılaşılmaktadır. Belgede dede adı olarak "Veliyyüddin" ismi bildirilerek, ${ }^{9}$ aslında Ahmed Efendi'nin aile adına işaret edildiği görülmektedir. ${ }^{10}$ Aynı kayıttan Ahmed Efendi'nin üç eşi bulunduğu anlaşılmaktadır. İlk eşi Mehmet Emin'in kızı Fatma, ikinci eşi Mehmed'in kızı Tevhide, üçüncü eşi Ahmed'in kızı Emine'dir. İlk eşinden boşanmış olan Ahmed Efendi'nin ikinci ve üçüncü eşlerinden toplam yedi çocuğu bulunmaktadır. İkinci eşinden Ali, Mustafa, Ayşe, Zarife; üçüncü eşinden Hasan, Hüseyin ve Ahmed isimli çocukları olmuştu.

T. Riley), C. II, Londra 1855, s. 4. Kale hakkında daha tafsilatlı bilgi için bkz. Erdal Eser, "Kinolis Kalesi”, Hacettepe Üniversitesi Edebiyat Fakültesi Dergisi, C. 21, S. 2 (2004), s. 171-194.

${ }^{4}$ BOA, NFS, nr. 824, s. 50.

5 İstefan da bölgedeki eski iskan merkezlerinden biriydi. Nitekim Plinius burayı Kinoli ile birlikte, "Stephane" adıyla anmaktadır. Bkz. The Natural History of Pliny, gös. yer.

${ }^{6}$ Bolu Eyaleti dahilinde kain Sinop Sancăğ kazalarından İstefan Kazası'na tâbi Zaviye Divanı... Bkz. BOA, ML.VRD.TMT (Maliye, Varidat Muhasebesi Temettuat Defterleri), nr, 3899, s. 2.

${ }^{7}$ Yine XIX. yüzyılın ilk yarısına ait nüfus kayıtlarından bu durum tespit edilebilmektedir. Bkz. BOA, NFS, nr. 831.

${ }^{8}$ BOA, İ.ŞD (İrade, Şura-yı Devlet), nr. 98/5849, 1-4, (2-24 Aralık 1889). İstefan'ın idarî merkezi modern Sinop'un batısında yer alan bugünkü Çaylığlu Köyü'dür. Bkz. Index Anatolicus: Türkiye Yerleşim Birimleri Envanteri, http://www.nisanyanmap.com/?yer=35561\&haritasi=ayanc\%C4\%B1k erişim 1 Ocak 2012.

${ }^{9}$ BOA, MŞH-SCD (Meşihat, Şeriyye Sicili Defterleri), nr. 7669, s. 27, kayıt nr. 63.

${ }^{10}$ Nitekim günümüzde de söz konusu Ahmed Efendi'nin soyundan gelen ve "Velioğulları" adıyla anilan bir aile mevcuttur. 
Velioğlu Ahmed Efendi’ye dair kadı sicilleri, kaza müdürünün 7 Haziran 1854 (11 Ramazan 1271) ${ }^{11}$ Çarşamba günü öldürüldüğünü göstermektedir. Dava tutanağına olay ayrıntılarıyla yansımıştır. Buna göre Ahmed Efendi, iftar daveti sebebiyle gittiği yakınlardaki Tolay Köyü’nde Kalafatoğlu Çırakçı Mehmed'in evinde teravih namazı kıldırdığı sırada otururken (cülus/kuud) kapıdan çifte ateşi ile sağ göğsünün üstünden yaralanmış ve olay yerinde hayatını kaybetmiştir. Olayın görgü tanıkları mücrimin İstefan Kazası'na bağlı Bugar Divanı'ndaki Uluza Köyü sakinlerinden Mehmed'in oğlu Merizoğlu Mustafa olduğunu bildirmişler, Merizoğlu Mustafa da suçunu mahkemede itiraf etmiştir. Ahmed Efendi'nin varisleri adına eşleri mücrimin derhal idam edilmesini istemişler, mahkeme de bu talebe olumlu cevap vermiştir. ${ }^{12}$

Söz konusu mahkeme kaydı bu cinayetin sebepleri hakkında her hangi bir malumat sunmamaktadır. Ancak kayıtlar, Ahmed Efendi'nin varislerinin olayın arkasında başkalarının olduğunu düşündüklerini göstermektedir. Nitekim ilk mahkemenin sonuçlanmasından kısa bir süre sonra Kastamonu Valisi İsmet Paşa'ya müracaat eden Emine Hatun, kocasını öldüren Merizoğlu Mustafa'yı bu suçu işlemeye Şükuroğlu Mehmed Ağa'nın azmettirdiğini iddia etmişti. Ancak daha sonra bu suçlamadan, buna ilişkin dava ve tüm taleplerinden, tarafların her ikisinin de hazır bulundurulduğu bir ortamda, kendisi adına asaleten ve çocukları adına velayeten, karşı1ıksız olarak vazgeçmişti. ${ }^{13}$

Ahmet Efendi'nin ailesinin ısrarı sonuç vermiş, tahkikat derinleştirilerek yeni bulgular elde edilmişti. 8 Kasım 1854 tarihinde İstanbul'dan, Sinop'a ve eyalet merkezi olan Kastamonu'ya gönderilen bir yazıya ${ }^{14}$ göre, cinayeti maktul Velioğlu Ahmet Efendi'den önceki kaza müdürü olan Arabacığlu Mehmed ile amcaları Hasan, Osman ve kardeşi Ali'nin azmettirdiği belirlenmişti. Buna göre söz konusu kişiler, cinayet için Katil Merizoğlu Mustafa ve arkadaşı Deli

\footnotetext{
${ }^{11}$ Söz konusu belgede 11 Ramazan 1271 tarihi gösterilmekteyse de daha sonra tutulan kayıtların tarihi ve bu kayıtlardaki atıflar ile kronolojik süreç dikkate alındığında olayın 11 Ramazan 1270 tarihinde cereyan ettiği anlaşılmaktadır.

${ }^{12}$ BOA, $M S S H-S C D$, nr. 7669, s. 27, kayıt nr. 63.

${ }^{13}$ BOA, $M S ̧ H-S C D$, nr. 7669, s. 55, kayıt nr. 80.

${ }^{14}$ BOA, A.MKT.MVL, nr. 68/85.
} 
Hüseyin'e 1.000 kuruş verme vaadinde bulunmuşlardı. Belgeden ulaşılan kıymetli bilgiler bunlarla da sınırlı değildir. Arabacıŏgullarını böylesi bir cinayeti tezgâhlamaya iten sebepler de açıklanmaktadır. Arabacıŏglu Mehmed vazifesi sırasında bazı usulsüzlüklere karışmış ve yaklaşık 87.000 kuruşu zimmetine geçirmişti. Bu tabii olarak görevinden azline neden olmuştu. Yine belgeye göre Arabacıoğlu Mehmed söz konusu gelişmeler karşısında halefi Velioğlu Ahmed Efendi'yi sorumlu tutmuş ve intikam almak istemişti. Bu durum maktul Ahmet Efendi'nin kaza idaresinde husule gelen usulsüzlüklerin su yüzüne çıkarılmasında rol oynadığını düşündürmektedir.

Cinayet soruşturması kapsamında zimmetine geçirdiği meblağ karşıllı̆ında Arabacıoğlu Mehmed'in Ayancık'taki mallarına ve parasına el konulması, tutarın karşılanamaması halinde kefillerinden tazmin edilmesine karar verilmiştir. Cinayeti tertipleyen Arabacığullarının her biri kısa sürede yakalanmış ve işledikleri suça karşı1ık olarak beşer yıl müddetle küreğe vurulması emredilmiştir. Dahası cezaları bitince mülklerinden sürülmelerine hükmedilmiştir. Ayrıca katile yardım ve yataklık eden Deli Hüseyin'in firar ettiği bildirilmiş, gerekli önlemlerin alınarak yakalanması istenmiştir.

Kastamonu'dan İstanbul'a gönderilen 11 Haziran 1855 tarihli yazıda azmettiricilerin Kastamonu'da hapsedildiği; ancak bunlardan Osman'ın hastalanarak öldüğü, firarî Deli Hüseyin'in yakalandığı ve diğer Arabacığullarının da İstanbul'a gönderileceği bildirilmektedir. ${ }^{15}$

Sonuçta görevini kötüye kullanan bir idarecinin ihtirası dürüst bir devlet adamının katline yol açmış, yöredeki varlıklı ailelerden birisini neredeyse yok olmanın eşiğine getirmişti. XIX. yüzyılın ortalarında meydana gelen bu trajik olay günümüzde hâlâ yöre halkının hafızasında yer almaktadır. Nitekim araştırmanın çıkış noktası da bu husus olmuştur. Yöredeki köklü ailelere ait hatıralara dair izlerin arşiv vesikalarından tespiti, şüphesiz yerel tarih araştırmaları açısından kıymet arz etmektedir.

${ }^{15}$ BOA, $M V L$, nr. 215/25. 


\section{Kaynaklar}

\section{Arşiv vesikaları:}

Başbakanlık Osmanlı Arşivi,

İrade, Şura-yı Devlet tasnifi:

nr. 98/5849, 1-4, (2/24 Aralik 1889).

Maliye, Varidat Muhasebesi Temettuat Defterleri tasnifi:

nr, 3899.

Meclis-i Vâlâ tasnifi:

nr. $215 / 25$.

Mektubî Kalemi Evrakı, Meclis-i Vâlâ tasnifi:

nr. $68 / 85$.

Meşihat, Şeriyye Sicili Defterleri tasnifi:

nr. 7669.

Nüfus Defterleri tasnifi:

nr. 824; nr. 831.

Yayımlanmış kaynaklar ve araştırma inceleme eserler:

Pliny, The Natural History of Pliny, (haz. John Bostock, H. T. Riley), C.

II, Londra 1855.

Erdal Eser, "Kinolis Kalesi”, Hacettepe Üniversitesi Edebiyat Fakültesi Dergisi, C. 21, S. 2 (2004), s. 171-194.

\section{Diğer:}

Index Anatolicus: Türkiye Yerleşim Birimleri Envanteri, http://www.nisanyanmap.com/?yer=35561\&haritasi=ayanc\% $\%$ C4 \%B1k erişim 1 Ocak 2012 